\title{
The effects of the choice of the femoral head in hip hemiarthroplasty on radiological and clinical outcomes
}

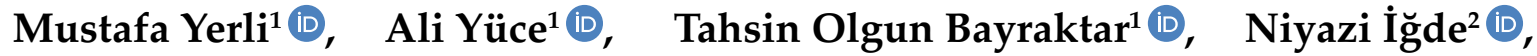 \\ Bülent Karslıŏ̆lu ${ }^{\text {(D) }}$ Nazım Erkurt ${ }^{1}$ (D), Mustafa Buğra Ayaz ${ }^{1}$ (D)

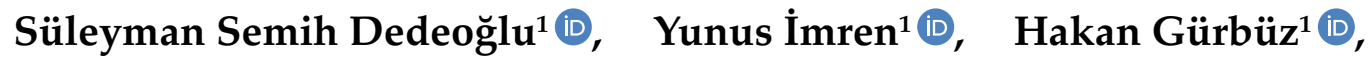

1 Prof. Dr. Cemil Taşcıoğlu City Hospital Department of Orthopedics and Traumatology, İstanbul, Turkey

2 Akçakale State Hospital Department of Orthopedics and Traumatology, Şanlıurfa, Turkey

\begin{abstract}
Background: A displaced femoral neck fracture in patients over 70 years of age is a severe injury that affects the patient's quality of life. It is associated with increased morbidity and increased risk of mortality.

Methods: The cases were divided into a monopolar group $(\mathrm{n}=167)$ and a bipolar group $(\mathrm{n}=175)$. Data on age, gender, ASA scores, length of stay, and other diseases were obtained from the patients' files. Dislocation, infection and periprosthetic fracture rates were examined by examining the outpatient records of the patients in the postoperative period.
\end{abstract}

Results: The mean age of all patients included in the study was $79.7 \pm 8.16$ years. $62.3 \%(n=213)$ of the patients were female and $37.7 \%$ ( $n=129$ ) were male. There was no significant difference between the patients in the monopolar group and the bipolar group regarding complications ( $\mathrm{p}=0.743$ ). The 30 -day mortality rates of the patients in the monopolar group were significantly higher than those in the bipolar group $(\mathrm{p}=0.041)$.

Conclusions: The use of the bipolar head in the surgical treatment of geriatric displaced femoral neck fractures with hemiarthroplasty may not provide any advantage in terms of functionality or complications.

Keywords: Femoral Neck Fracture, Geriatric, Hemiarthroplasty, Monopolar, Bipolar. 


\section{INTRODUCTION}

Femoral neck fractures (FNF) have a high incidence and it is a severe and life-threatening health problem with a 1-year mortality rate of 17 to $24 \%(1,2)$. A displaced FNF in patients over 70 years of age is a severe injury that affects the patient's quality of life and is associated with increased morbidity and increased risk of mortality $(3,4)$. Open reduction internal fixation (ORIF) is rarely used in the elderly, given the chance of nonunion and worse patient outcomes after avascular necrosis and conversion to arthroplasty after a failed ORIF (3). In these patients, arthroplasty is now routinely performed $(1,5)$.

Total hip arthroplasty (THA) or hemiarthroplasty (HA) are available as arthroplasty options in patients with geriatric FNF (6,7). HA is still considered the mainstay therapy for FNF in less active, elderly patients who do not impose high forces on the prosthetic joint; more than $75 \%$ of geriatric FNF are treated with HA (8-10).

Theoretically, bipolar head compared to monopolar head in the selection of femoral head in HA; it has the theoretical advantage of reducing acetabular cartilage wear and reducing the rate of dislocation thanks to its dual bearing system. In addition, the costs of the bipolar head are higher than the monopolar head (11). It is uncertain whether the benefits of the bipolar prosthesis justify its cost $(1,11,12)$.

Our study hypothesis is that bipolar head use is not superior to monopolar head use in terms of complication and mortality rates in patients who have undergone hip HA. In light of this hypothesis, it was aimed to examine the effect of femoral head selection on these data by retrospectively looking at the postoperative data of the patients included in the study.

\section{MATERIALS AND METHODS}

The ethical committee approval of Health Sciences University Prof. Dr. Cemil Taşçığlu City Hospital was obtained for conducting the research (Date: 30/06/2020, decision no:293). This study was performed within the guidelines of the Helsinki Declaration. The files of patients who underwent HA with the diagnosis of FNF between January 2014 and December 2019 were reviewed. Patients with pathological fractures, patients who underwent THA, patients who underwent osteosynthesis, patients with neurovascular deficits, patients with neurologic disorders, patients younger than 65 years of age, and those who were missing follow-up were excluded from the study. The files of 342 patients aged 65 and over and diagnosed with femoral neck fracture who underwent HA were included in the study after the application of exclusion criteria. The cases were divided into two groups: a monopolar group $(n=167)$ and a bipolar group $(n=175)$ according to the characteristics of the applied femoral head.

All of the cases were operated under spinal or general anesthesia in the lateral decubitus position. Surgery was performed with a posterolateral approach. After the femoral head was excised, the femoral medulla was prepared by carving. After the application of the cemented femoral stem in appropriate sizes, the right size of the femoral neck and head was applied. Head selection (bipolar or monopolar) varied according to the surgeon's choice. After the prosthesis application, stability control was made by examination; then, a wound drain was placed, and the layers were closed anatomically.

The wound drain was removed within 48 hours postoperatively. If the cases did not have an exceptional situation to prevent them, they were mobilized with the help of a walker on the first postoperative day. The exercises that should be done and the movements that should not be done were explained to the patients by the physician. Enoxaparin $0.4 \mathrm{cc} /$ day was administered to the patients postoperatively for the prophylaxis of venous thromboembolism, and anti-embolic stockings were worn.

Data on age, gender, American Society of Anesthesiology (ASA) score, length of stay, and other diseases were obtained from the files of the patients. INFINITT PACS (Picture Archiving Communication Systems) imaging program used in our hospital was used for radiographic evaluations. The surgical records of the patients included in the study were examined and divided into two groups according to the applied femoral heads. Dislocation, infection and periprosthetic fracture rates were analysed by reviewing the outpatient records of the patients in the postoperative period. Pelvic anteroposterior radiographs taken in the 6th month postoperatively of the survivors were evaluated for acetabular erosion. Again, the values of Harris hip scores were examined at the 6th-month outpatient controls. Using the hospital registry system, the death dates of the patients were reviewed to calculate the 30-day, 90-day and 1-year mortality. Then, the data of the bipolar and monopolar groups were compared statistically.

Statistical analyses were performed with SPSS version 25.0 software. The descriptive data were presented using mean, standard deviation, median and interquartile range (IQR) values. The compliance of the variables with normal distribution was examined with histogram graphs and the Kolmogorov-Smirnov test. The independent group t-test was used when evaluating the normally distributed (parametric) variables between the groups. The Mann- 
Whitney $\mathrm{U}$ test and Kruskal Wallis $\mathrm{H}$ test assessed the non-normally distributed (non-parametric) variables between the groups. The Chi-square and likelihood ratio tests were used when determining the categorical data. Cases where the $\mathrm{p}$-value was under 0.05 were accepted as statistically significant.

This study was approved by the clinical research ethics committee of the Health Sciences University, Prof. Dr. Cemil Taşcıoğlu City Hospital (Date: 30.06 .2020 number: 2020/293) and written consent was obtained from all patients participating in the study.

\section{RESULTS}

The mean age of all patients included in the study was $79.7 \pm 8.16$ years. $62.3 \%(n=213)$ of the patients were female and $37.7 \%(n=129)$ were male. There were fractures in the right hip in $45.9 \%(n=157)$ and left hip in $54.1 \% \quad(n=185)$ of the cases. The mean age, gender, fracture types and distribution of ASA scores of the patients in both groups are shown in Table 1.

The distribution of complication and mortality rates obtained as a result of the collected data of the patients included in the study is shown in Table 2.

Table 1. Demographic data of the patients included in the study by groups

\begin{tabular}{|c|c|c|c|}
\hline & $\begin{array}{l}\text { Monopolar group } \\
(n=167)\end{array}$ & $\begin{array}{l}\text { Bipolar group } \\
(n=175)\end{array}$ & p value \\
\hline Age (Mean, SD) & $81.57 \pm 7.56$ & $77.99 \pm 8.34$ & $<0.001^{*}$ \\
\hline $\begin{array}{l}\text { Gender }(\mathrm{n},[\%]) \\
\text { Female } \\
\text { Male }\end{array}$ & $\begin{array}{l}104[62.3 \%] \\
63[37.7 \%]\end{array}$ & $\begin{array}{l}109[62.3 \%] \\
66[37.7 \%]\end{array}$ & $0.998^{* *}$ \\
\hline $\begin{array}{l}\text { Side }(n,[\%]) \\
\text { Right } \\
\text { Left }\end{array}$ & $\begin{array}{l}77[46.1 \%] \\
90[53.9 \%]\end{array}$ & $\begin{array}{l}80[45.7 \%] \\
95[54.3 \%]\end{array}$ & $0.942^{* *}$ \\
\hline $\begin{array}{c}\text { ASA (n, [\%]) } \\
\text { I } \\
\text { II } \\
\text { III } \\
\text { IV } \\
\end{array}$ & $\begin{array}{l}21[12.6 \%] \\
49[29.3 \%] \\
73[43.7 \%] \\
24[14.4 \%] \\
\end{array}$ & $\begin{array}{l}18[10.3 \%] \\
60[34.3 \%] \\
70[40 \%] \\
27[15.4 \%]\end{array}$ & $0.707^{* *}$ \\
\hline $\begin{array}{l}\text { Number of comorbidity }(\mathrm{n},[\%]) \\
0-1 \\
>2\end{array}$ & $\begin{array}{l}38[22.8 \%] \\
129[77.2 \%]\end{array}$ & $\begin{array}{l}22[12.6 \%] \\
153[87.4 \%]\end{array}$ & $0.013^{* *}$ \\
\hline
\end{tabular}

* Student's t-test ** Pearson Chi-Square test

Table 2. Distribution of complications and mortality rates in patients according to groups

\begin{tabular}{|l|l|l|l|}
\hline & $\begin{array}{l}\text { Monopolar group } \\
(\mathrm{n}=167)\end{array}$ & $\begin{array}{l}\text { Bipolar group } \\
(\mathrm{n}=175)\end{array}$ & p value \\
\hline Complication (n, [\%]) & $14[8.4 \%]$ & $13[7.4 \%]$ & $0.743^{*}$ \\
\hline Dislocation (n, [\%]) & $10[6 \%]$ & $5[2.9 \%]$ & $0.158^{*}$ \\
\hline Periprostetic Joint Infection (n, [\%]) & $4[2.4 \%]$ & $8[4.6 \%]$ & $0.274^{*}$ \\
\hline $\begin{array}{l}\text { Periprostetic } \\
\text { Fracture (n, [\%]) }\end{array}$ & $1[0.6 \%]$ & $1[0.6 \%]$ & $0.739^{* *}$ \\
\hline $\begin{array}{l}\text { Acetabular } \\
\text { erosion (n, [\%]) }\end{array}$ & $5[3 \%]$ & $1[0.6 \%]$ & $0.11^{* *}$ \\
\hline Harris Hip Score (mean, SD) & $78.99 \pm 2.04$ & $78.91 \pm 1.94$ & $0.713^{* * *}$ \\
\hline $\begin{array}{l}\text { Mortality (n, [\%]) } \\
\text { 30-day } \begin{array}{l}\text { 90-day } \\
\text { 1-year }\end{array}\end{array}$ & $\begin{array}{l}25[12 \%] \\
20[16.4 \%]\end{array}$ & $\begin{array}{l}10[5.7 \%] \\
17[11.5 \%]\end{array}$ & $\begin{array}{l}0.041^{*} \\
0.164^{*} \\
0.262^{*}\end{array}$ \\
\hline
\end{tabular}

*Pearson Chi-Square test

${ }^{* *}$ Fisher's Exact test $\quad$ ***Student's t-test 


\section{DISCUSSION}

Complication rates may increase with osteosynthesis treatment due to poor bone quality in elderly patients (12). Hemiarthroplasty for displaced femoral neck fractures in geriatric patients is an effective surgical treatment method that requires less revision surgery, less pain, higher satisfaction with the outcome of the operation, and a higher quality of life, without any difference in mortality $(13,14)$. It has been produced with the theoretical design that the bipolar head can cause a decrease in acetabular wear and dislocation rates in hip hemiarthroplasty applications $(9,15,16)$. However, the advantages in this regard are not clear, and there are results in the literature that even the bipolar head increases prosthesis dislocation compared to the monopolar head $(9,11)$. In our study, there was no difference between the characteristics of the selected head component and the complication rates.

On the other hand, the mean age was significantly higher in the monopolar head group. Increased age may be associated with decreased activity. As a result of this situation, the similarity between the two groups in complication rates may have emerged. Perhaps in older patients with less activity, monopolar head selection may be the appropriate choice.

Functionally impaired patients have disadvantages such as occasional pain, acetabular erosion or implant loosening after HA, and the need for revision surgery as a result (7). The rates of acetabular erosion reported in the literature are variable and range from $0.6 \%$ to approximately $100 \%$ in long-term follow-up (17-19). At the same time, head selection may not affect revision rates due to this acetabular erosion (9). Although there was no relationship between acetabular erosion and its chief component in our study, it included early followup. For this reason, we believe that the selection of parts in the early period is not essential in need for premature acetabular erosion and the related revision.

Cemented HA may be associated with less pain and better functional scores $(20,21)$. Also, cemented femoral stem may be related to lower re-operation rates $(13,22)$. Although cemented stem was applied in all cases in our study; We believe that cemented femoral stem application is the application that should be preferred in geriatric patients due to reduced pain, early mobility advantage and reduced re-operation rates.

According to the results of a study comparing the functional results of bipolar and monopolar HA in femoral neck fractures, it seems that there is no advantage in using a bipolar endoprosthesis in the treatment of displaced FNF in the elderly. In addition, the extra cost of bipolar endoprostheses does not seem to warrant its use (11). Considering the results of our study, we also believe that the bipolar head does not provide a functional advantage. Perhaps the head choice in hemiarthroplasty is the result of the surgeon's belief in the theoretical advantages of bipolar treatments. On the other hand, the fact that the patients who underwent monopolar head in our study were older than the bipolar group may result from this belief. The fact that monopolar chief surgeons in older patients preferred it may have caused this situation.

The shortcomings of our study can be counted as being retrospective, inability to compare cemented and uncemented femoral stem applications, and short follow-up period. Another critical limitation of ours is that we could look at the acetabular erosions of the patients included in the study only with the 6th month postoperative radiographs. A prospective study can reveal these deficiencies, including different prosthesis selections and different groups with longterm follow-up.

In conclusion, using the bipolar head in the surgical treatment of geriatric displaced FNF with HA may not provide any advantage in terms of functionality or complications. Perhaps the choice of the femoral head in HA is simply a result of the surgeon's theoretical belief in the advantages of the bipolar head.

\section{Declarations}

The authors received no financial support for the research and/or authorship of this article. There is no conflict of interest.

This study was approved by the clinical research ethics committee of the Health Sciences University, Prof. Dr. Cemil Taşcıŏglu City Hospital (Date: 30.06.2020 number: 2020/293) and written consent was obtained from all patients participating in the study. 


\section{Author's Contribution}

M.Y. and M.B.A. designed the protocol, reviewed the literature, analyzed the data, and critically reviewed and wrote the manuscript. A.Y., N.E. and T.O.B. analyzed the data, reviewed the literature, and critically reviewed and wrote the manuscript. B.K and S.S.D. designed the protocol, collected and analyzed the data, and reviewed the literature. Y.I. and N.İ. collected and analyzed the data. H.G. collected and analyzed the data. All authors read and approved the final manuscript.

\section{REFERENCES}

1. Guyen O. Hemiarthroplasty or total hip arthroplasty in recent femoral neck fractures? Orthop Traumatol Surg Res. 2019;105(1S): 95-101.

2. Tanoğlu O, Arıcan G, Özmeriç A, Sahin O, Iltar S, Alemdaroğlu BK. Predictors of early mortality in geriatric patients after hemiarthroplasty for femoral neck fracture. Acta Med Alanya. 2020;4(3):220-225.

3. Kristensen TB, Dybvik E, Kristoffersen M, Dale H, Engesæter LB, Furnes $\mathrm{O}$, et al. Cemented or Uncemented Hemiarthroplasty for Femoral Neck Fracture? Data from the Norwegian Hip Fracture Register. Clin Orthop Relat Res. 2020;478(1):90-100.

4. Vatansever A, Öziç U, Okçu G. Assessment of quality of life of patients after hemiarthroplasty for proximal femoral fractures. Acta Orthop Traumatol Turc 2005;39(3):237-242.

5. Kaya Ş, Özdemir H, Dabak AY. İleri yaş hastalarda çimentolu ve çimentosuz hemiartroplasti sonuçlarının karşılaştırılması. Dicle Medical Journal. 2017;44(3):233-241.

6. McKinley JC, Robinson CM. Treatment of displaced intracapsular hip fractures with total hip arthroplasty: comparison of primary arthroplasty with early salvage arthroplasty after failed internal fixation. J Bone Joint Surg Am. 2002;84(11):2010-5.

7. Ogawa T, Yoshii T, Moriwaki M, Morishita S, Oh Y, Miyatake K, et al. Association between Hemiarthroplasty vs Total Hip Arthroplasty and Major Surgical Complications among Patients with Femoral Neck Fracture. J Clin Med. 2020;9(10):3203.

8. Wu X, Wang Y, Sun W, Tan M. Cemented and uncemented hemiarthroplasty for femoral neck fracture in elderly patients: a systematic review and meta-analysis. Aging Clin Exp Res. 2021;33(8):2087-111.

9. Grosso MJ, Danoff JR, Murtaugh TS, Trofa DP, Sawires AN, Macaulay WB. Hemiarthroplasty for Displaced Femoral Neck Fractures in the Elderly Has a Low Conversion Rate. J Arthroplasty. 2017;32(1):150-4.

10. Aksu N, Işıklar ZU. Kalça kırıkları. TOTBID Dergisi. 2008;7(1-2):8-19.

11. Ong BC, Maurer SG, Aharonoff GB, Zuckerman JD, Koval KJ. Unipolar versus bipolar hemiarthroplasty: functional outcome after femoral neck fracture at a minimum of thirty-six months of followup. J Orthop Trauma. 2002;16(5):317-22.

12. Shetty $\mathrm{SH}$, Dhond $\mathrm{AB}$, Agarwal $\mathrm{A}$, Kharat $\mathrm{A}$, Singh A. Intertrochanteric fracture of femur in elderly-A comparative analysis between hemiarthroplasty and osteosynthesis. Int J Orthop Sci 2017;3(1):449-52.

13. Gjertsen JE, Vinje T, Engesaeter LB, Lie SA, Havelin LI, Furnes O, et al. Internal screw fixation compared with bipolar hemiarthroplasty for treatment of displaced femoral neck fractures in elderly patients. J Bone Joint Surg Am. 2010;92(3):619-28.
14. Dai Z, Li Y, Jiang D. Meta-analysis comparing arthroplasty with internal fixation for displaced femoral neck fracture in the elderly. J Surg Res. 2011;165(1):68-74

15. Zehir S, Şahin E, Sipahioğlu S, Azboy İ, Yar Ü. Femur boyun kırıklarına parsiyel protez uygulamasında anterior ve posterior kapsüler açılımın sonuçları. Ulus Travma Acil Cerr Derg. 2013;19(5):456-462.

16. Sevinç HF. Dissociation of bipolar components following bipolar hemiarthroplasty: A report of two different cases and review of the literatüre. Ulus Travma Acil Cerrahi Derg, 2021;27(5):600-603.

17. Haidukewych GJ, Israel TA, Berry DJ. Long-term survivorship of cemented bipolar hemiarthroplasty for fracture of the femoral neck. Clin Orthop Relat Res. 2002;(403):118-26.

18. Solak Ş, Oğuz T, Bektaşer B, Adabağ C. Comparison of the two types of endoprosthesis in the treatment of intracapsular hip fractures in elderly patients. Joint Dis Rel Surg 2002;13:1-4.

19. Bölük K, Bilgen MS, Durak K. İleri yaş ayrılmış femur boyun kırıklarında unipolar ve bipolar protez uygulamaları. Uludağ Üniversitesi Tıp Fakültesi Dergisi. 2008;34(2):41-44.

20. Khan RJ, MacDowell A, Crossman P, Keene GS. Cemented or uncemented hemiarthroplasty for displaced intracapsular fractures of the hip--a systematic review. Injury. 2002;33(1):13-7.

21. Parker MJ, Gurusamy KS, Azegami S. Arthroplasties (with and without bone cement) for proximal femoral fractures in adults. Cochrane Database Syst Rev. 2010;(6):CD001706.

22. Moerman S, Mathijssen NMC, Niesten DD, Riedijk R, Rijnberg WJ, Koëter $\mathrm{S}$, et al. More complications in uncemented compared to cemented hemiarthroplasty for displaced femoral neck fractures: a randomized controlled trial of 201 patients, with one year follow-up. BMC Musculoskelet Disord. 2017;18(1):169. 